\title{
Multi-scale ant diversity in savanna woodlands: an intercontinental comparison
}

\author{
RICARDO I. CAMPOS, ${ }^{1 \star}$ HERALDO L. VASCONCELOS,${ }^{2}$ ALAN N. ANDERSEN,${ }^{4}$ \\ TIAGO L. M. FRIZZO ${ }^{2}$ AND KELLY C. SPENA ${ }^{3}$ \\ ${ }^{1}$ Departamento de Biologia Geral, Universidade Federal de Viçosa (UFV), 36570-000, Viçosa, MG, \\ Brazil (Email: ricardo.campos@ufv.br); ${ }^{2}$ Instituto de Biologia, Universidade Federal de Uberlândia \\ (UFU), Uberlândia, MG, and ${ }^{3}$ Universidade de Mogi das Cruzes (UMC), Campus 1, Núcleo de \\ Ciências Ambientais, Mogi das Cruzes, São Paulo, Brazil; and ${ }^{4}$ CSIRO Sustainable Ecosystems, \\ CSIRO Tropical Ecosystems Research Centre, Winnellie, Northern Territory, Australia
}

\begin{abstract}
Ecological patterns and processes are highly scale-dependent, but few studies have used standardized methodology to examine how scale dependency varies across continents. This paper examines scale dependency in comparative ant species richness and turnover in savannas of Australia and Brazil, which are well-matched climatically but whose ant faunas have contrasting biogeographic origins. The study was conducted in savanna woodland near Darwin in northern Australia and Uberlândia in central Brazil. The sampling design consisted of eight 400-m line transects, four in each continent, with eight pitfall traps located on and around each of 20 trees evenly spaced along each transect. Ant richness and species turnover were compared at three spatial scales: pitfalls associated with a tree, trees within a transect and transects within a savanna. The composition of the Australian and Brazilian savanna ant faunas was broadly similar at the subfamily level, despite the very low proportion of shared genera and species. The ground and arboreal ant faunas were very distinct from each other in both savannas, but especially in Brazil. Overall ant abundance was almost three times higher in Australia than in Brazil, both on the ground and on vegetation, but overall species richness was higher in Brazil (150 species) than in Australia (93). There was no significant difference in the mean number of species per pitfall trap, but the mean species richness was significantly higher in Brazil than in Australia at both the tree and transect scales. We attribute these scale-dependent intercontinental differences to biogeographical and historical factors in Brazil that have led to a large regional pool of arboreal species of rainforest origin. Our study underlines the importance of biogeographical context when conducting comparative analyses of community structure across biogeographical scales, and highlights the importance of process acting at regional scales in determining species richness in ant communities.
\end{abstract}

Key words: beta diversity, biogeography, community structure, formicidae, scale dependency.

\section{INTRODUCTION}

The effect of spatial scale on ecological patterns is a key issue in community ecology and biogeography, and studies comparing community structure at different spatial scales have made important contributions to ecological theory (Ricklefs 1987; Wiens 1989; Lawton 1999; Spiesman \& Cumming 2008). The pervasiveness of scale dependency (Wiens 1989) is a key factor limiting the generality of ecological patterns and processes (Lawton 1999). For example, it is particularly common for the factors controlling species diversity at local and regional scales to be quite different (Ricklefs 1987), so that comparative analyses of species diversity can arrive at different conclusions depending on the scale of analysis. Moreover, such comparative analyses are frequently confounded by

${ }^{\star}$ Corresponding author.

Accepted for publication February 2011. the different scales at which species have been sampled. In order to develop a mechanistic understanding of the relative importance of different factors driving comparative species diversity, it is important to collect standardized data at comparable spatial scales, and to repeat this at different scales (Whittaker et al. 2001).

Several workers have noted the importance of spatial scale for ant communities (Andersen 1997a; Lawton 1999; Gotelli \& Ellison 2002; Parr et al. 2005; Spiesman \& Cumming 2008), but there have been few studies purposely designed to investigate this (Kaspari et al. 2003). Here we report on such a study, which incorporates an intercontinental comparison between Australia and Brazil. Intercontinental comparisons of community structure have already been made for a number of taxa (e.g. Cody \& Mooney 1978), including ants (Andersen 1997b; Morton \& Davidson 1988); however, few of those comparisons have explicitly addressed scale dependency.

doi:10.1111/j.1442-9993.2011.02255.x 
Ant diversity shows a strong latitudinal gradient globally, reaching a maximum in the tropics (Ward 2000; Dunn et al. 2009). Most studies of tropical ant diversity have focused on rainforest, which supports a highly distinctive fauna both compositionally and functionally: local assemblages are exceptionally diverse, are highly segregated vertically, and contain few taxa from non-forest habitats (Wilson 1959; Brühl et al. 1998; Longino et al. 2002). However, the dominant tropical vegetation is savanna, characterized by sparse trees and continuous grass cover, whose open structure is driven by highly seasonal rainfall and high rates of disturbance, especially by fire (Huntley \& Walker 1982). Tropical savannas also possess very high ant diversity (Andersen 2000; Parr \& Chown 2001; da Silva et al. 2004; Vasconcelos \& Vilhena 2006), but the extent of vertical segregation varies markedly. Savannas in Australia and South Africa support few tree-nesting species, and the arboreal fauna is overwhelmingly dominated by ground-nesting species (Majer 1990; Parr \& Chown 2001; Andersen et al. 2006). In contrast, Brazilian savannas (cerrado) support an exceptionally diverse specialist arboreal ant fauna, dominated by taxa of rainforest origin (Ribas et al. 2003; da Silva et al. 2004; Vasconcelos \& Vilhena 2006; Campos et al. 2008).

Our understanding of intercontinental patterns of savanna ant diversity is limited to these general findings, and, as is the case for most taxa, detailed comparisons are confounded by highly variable sampling methodology and intensity. A comparison of Brazilian and Australian savannas is especially interesting because they are located at similar latitudes, are very similar in size (about $2000000 \mathrm{~km}^{2}$ ), and experience comparable rainfall and temperature regimes (Mott et al. 1985; Oliveira \& Marquis 2002). Conversely, their ant faunas have strikingly different biogeographic origins that reflect contrasting environments at the continental scale, and drive the representation of arboreal species described above. A large proportion of the Australian savanna ant fauna (such as the genera Iridomyrmex, Melophorus and Meranoplus) is arid-adapted, derived from that continent's vast central arid zone (Andersen 2000), and very few taxa have originated from tropical rainforest, whose extent in Australia is extremely limited (Taylor 1972). In contrast, Brazilian savannas contain few arid zone taxa but very many derived from tropical rainforest (e.g. Azteca, Cephalotes, Pseudomyrmex; see Kempf 1972; Brown 2000), as reflects their proximity to the Amazonian Basin to the north and the Atlantic rainforest to the south. Such contemporary biogeography is also reflected in the evolutionary histories of the two savannas, which were embedded in expansions and retractions of desert in Australia (Horton 1984) and rainforest in Brazil (Redford \& Fonseca 1986).

Here we used standardized sampling methodology to compare species richness in Australian and Brazil- ian savanna ant communities, and to examine how this comparison varies with spatial scale. The specific aims of this paper were to: (i) compare the taxonomic composition of Australian and Brazilian savanna ants; (ii) compare the extent of vertical segregation of ant communities between the two continents; (iii) compare ant species richness and species turnover at multiple spatial scales; and (iv) examine the extent to which intercontinental comparisons of ant diversity are scale-dependent.

\section{METHODS}

\section{Study area}

The study was conducted near Darwin $\left(12^{\circ} 24^{\prime} \mathrm{S}, 130^{\circ} 55^{\prime} \mathrm{E}\right)$ in northern Australia and near Uberlândia $\left(18^{\circ} 30^{\prime} \mathrm{S}\right.$, $\left.45^{\circ} 40^{\prime} \mathrm{W}\right)$ and Caldas Novas $\left(17^{\circ} 43^{\prime} \mathrm{S}, 48^{\circ} 42^{\prime} \mathrm{W}\right)$ in central Brazil. The temperature in Darwin ranges from an overnight minimum of $15^{\circ} \mathrm{C}$ in winter to a daytime maximum of $35^{\circ} \mathrm{C}$ in summer, and mean annual rainfall is $1600 \mathrm{~mm}$ with around $80 \%$ concentrated in the wet season between December and April. The regional climate in central Brazil is very similar to that of northern Australia, with mean annual precipitation around $1500 \mathrm{~mm}$, and rainfall concentrated in the summer wet season. Temperatures are also very similar, except that minimum overnight temperatures during the dry season are lower because of the lack of a coastal influence. The typical savanna vegetation in central Brazil is known as cerrado sentido restrito (Ribeiro \& Walter 1998) while in northern Australia it is called savanna woodland (Mott et al. 1985). The physiognomy of the cerrado is quite different to that of woodland savannas. The latter are composed of relatively tall and erect trees (mostly Eucalyptus tetrodonta and Eucalyptus miniata), whereas the cerrado presents short 'crooked' trees and a much higher woody species richness (Appendix S1; also see Table 1).

\section{Ant sampling}

Ant sampling was conducted along four 400-m transects in each country. Inter-transect distances ranged from 1 to $40 \mathrm{~km}$ in Australia and from 1 to $130 \mathrm{~km}$ in Brazil. A detailed characterization of each transect is presented in Table 1. Along each transect the nearest tree taller than $2 \mathrm{~m}$ was located at each $20 \mathrm{~m}$ interval $(n=20$ trees). Eight pitfall traps were established on and around each tree, four buried in the ground beneath the tree canopy and four fixed in the tree branches with masking tape. These eight traps will subsequently be referred to as a 'tree' (Appendix S2). The four traps placed on the ground were arranged in a $2 \times 2-\mathrm{m}$ grid established around each tree. The four arboreal traps were, whenever possible, placed in different tree branches and were at least $2 \mathrm{~m}$ apart from each other. Pitfall traps were $4-\mathrm{cm}$ diameter plastic containers partially filled with water and detergent. For each set of four ground and arboreal traps, two had their inner rims smeared with sardine oil, and two with honey, as ant attractants. Each trap was kept open for a 
Table 1. Vegetation description, dominant tree species in the canopy, number of tree species by transect and geographic coordinates from the eight transects located four in the Brazilian savanna and four in the Australian savanna

\begin{tabular}{|c|c|c|c|c|c|}
\hline Country & Transect & Vegetation & $\begin{array}{l}\text { Dominant } \\
\text { species in } \\
\text { the canopy }\end{array}$ & $\begin{array}{l}\mathrm{N}^{\circ} \text {. of } \\
\text { tree species } \\
\quad(n=20)\end{array}$ & Coordinates \\
\hline Australia & 1 & $\begin{array}{l}\text { Canopy approximately } 15 \mathrm{~m} \text { height } \\
\text { with } 15 \% \text { of foliage cover. }\end{array}$ & Eucalyptus tetrodonta & 9 & $12^{\circ} 24^{\prime} 38^{\prime \prime} \mathrm{S} 130^{\circ} 55^{\prime} 19^{\prime \prime} \mathrm{E}$ \\
\hline Australia & 2 & $\begin{array}{l}\text { Canopy approximately } 12 \mathrm{~m} \text { height } \\
\text { with } 15 \% \text { of foliage cover. }\end{array}$ & E. tetrodonta & 2 & $12^{\circ} 24^{\prime} 54^{\prime \prime} \mathrm{S} 130^{\circ} 55^{\prime} 58^{\prime \prime} \mathrm{E}$ \\
\hline Australia & 3 & $\begin{array}{l}\text { Canopy approximately } 15 \mathrm{~m} \text { height } \\
\text { with } 15 \% \text { of foliage cover. }\end{array}$ & E. miniata & 4 & $12^{\circ} 40^{\prime} 25^{\prime \prime} \mathrm{S} 131^{\circ} 4^{\prime} 7^{\prime \prime} \mathrm{E}$ \\
\hline Australia & 4 & $\begin{array}{l}\text { Canopy approximately } 20 \mathrm{~m} \text { height } \\
\text { with } 10 \% \text { of foliage cover. }\end{array}$ & E. tetrodonta/E. miniata. & 11 & $12^{\circ} 42^{\prime} 6^{\prime \prime} \mathrm{S} 130^{\circ} 58^{\prime} 14^{\prime \prime} \mathrm{E}$ \\
\hline Brazil & 1 & $\begin{array}{l}\text { Canopy approximately } 5 \mathrm{~m} \text { height } \\
\text { with } 15 \% \text { of foliage cover. }\end{array}$ & several & 12 & $19^{\circ} 10^{\prime} 01^{\prime \prime} \mathrm{S} 48^{\circ} 23^{\prime} 20^{\prime \prime} \mathrm{W}$ \\
\hline Brazil & 2 & $\begin{array}{l}\text { Canopy approximately } 4 \mathrm{~m} \text { height } \\
\text { with } 12 \% \text { of foliage cover. }\end{array}$ & several & 11 & $19^{\circ} 10^{\prime} 58^{\prime \prime} \mathrm{S} 48^{\circ} 23^{\prime} 87^{\prime \prime} \mathrm{W}$ \\
\hline Brazil & 3 & $\begin{array}{l}\text { Canopy approximately } 4 \mathrm{~m} \text { height } \\
\text { with } 10 \% \text { of foliage cover. }\end{array}$ & several & 13 & $17^{\circ} 43^{\prime} 75^{\prime \prime} \mathrm{S} 48^{\circ} 42^{\prime} 23^{\prime \prime} \mathrm{W}$ \\
\hline Brazil & 4 & $\begin{array}{l}\text { Canopy approximately } 4 \mathrm{~m} \text { height } \\
\text { with } 10 \% \text { of foliage cover. }\end{array}$ & several & 10 & $17^{\circ} 43^{\prime} 22^{\prime \prime} \mathrm{S} 48^{\circ} 42^{\prime} 02^{\prime \prime} \mathrm{W}$ \\
\hline
\end{tabular}

48-h period, and a total of 1280 pitfalls were sampled on and around 160 trees. We used published information (Andersen 2000; Schultz \& McGlynn 2000) combined with direct observations for $1 \mathrm{~h}$ on each tree to identify which species nest arboreally.

Ants were sampled during November and December (early rainy season) of 2005 in Brazil and during the same months and season of 2006 in Australia. All ants collected in traps were sorted to species, and where possible named, with species nomenclature following Bolton (2003). Species that could not be confidently named were assigned voucher codes. Voucher specimens of all Australian species are held at the CSIRO Tropical Ecosystems Research Centre, and Brazilian species in the Zoological Collection of the Federal University of Uberlândia.

\section{Data analysis}

The comprehensiveness of our sampling protocol was evaluated by constructing two sample (pitfall trap)-based accumulation curves (Gotelli \& Colwell 2001), one for Australia and the other for Brazil ( $n=640$ pitfalls each), using EstimateS 7.5 (Colwell 2004). A $t$-test was used to compare mean ant abundance at the pitfall trap scale, and mean species richness at the pitfall, 'tree' and transect scales (Appendix S2), between Australia and Brazil.

The taxonomic composition of the Australian and Brazilian faunas was compared by analysing the proportions of species and individuals per subfamily using a Chi-squared contingency table (Zar 1999). The two faunas are known to be very distinct at the genus level, and no native species are shared, so formal analyses were not conducted at these levels. The frequency of arboreally nesting species, and of species from rainforest taxa, was compared, but did not require formal statistical analysis.

The extent of vertical segregation (ground and arboreal) of ant species was investigated using multidimensional scaling
(MDS) in two dimensions, on log-transformed species abundance data from ground and arboreal traps. MDS was based on a Bray-Curtis dissimilarity matrix, and performed using the software Systat 10 (SPSS 2000). The effect of stratum on the species composition was then assessed by MANOVA (Zar 1999) using the MDS axes as dependent variables. For this former test the 'trees' were considered as blocks to assess only the effect of treatment (stratum) independent from the effect of plant species (for block designs see Clarke \& Warwick 2001).

We used additive diversity partitioning (Veech et al. 2002) for a comparative analysis of species diversity and species turnover at different spatial scales in Brazil and Australia, using combined ground and arboreal data. Diversity partitioning is a method of decomposing total species richness (gamma diversity) into the components of mean diversity within samples (alpha diversity) and diversity among samples (beta diversities). For the purpose of our analyses, the mean number of species per pitfall represented $\alpha$ diversity, whereas $\beta 1, \beta 2, \beta 3$ represented the diversity among pitfalls within trees, among trees within transects and among transects within countries, respectively. The analyses were performed using the software Partition 3.0 (Veech \& Crist 2009). This program calculates alpha and beta diversity and uses a randomization method for evaluating the statistical significance of the diversity components. The randomization procedure produces diversity partitions that would be expected from randomized data (i.e. a null model) and then compare these expected partitions with the actual partitions. We used individual-based randomizations (based on 1000 randomizations), which reassign each individual of the dataset to any sample (Veech \& Crist 2009).

Because transects in the two countries showed different levels of geographic separation, the extent to which species turnover was related to geographic separation was examined by calculating the dissimilarity for each pair of transects in each country. Dissimilarity between transects was calculated using the Simpson index, which is less biased by variations in 
species richness than other commonly used similarity indices (Koleff et al. 2003). The index was calculated using the following equation: $\min (b . c) /(\min (b, c)+a)$, where $a$ is the number of species shared between two transects, and $b$ and $c$ are the number of exclusive species in each transect (and min denotes the smallest value).

\section{RESULTS}

\section{Faunal composition}

In total, 185334 individual ants representing 242 species, 48 genera and 7 subfamilies were collected in traps (see Appendix S3). In Australia, the richest genera were Monomorium (13 species) and Polyrhachis (9), and in Brazil Camponotus (27 species) and Pheidole (23). Despite only eight (16\%) genera co-occurring in Australia and Brazil, the composition of the two faunas was extremely similar at the subfamily level when considering species richness $\left(\chi^{2}=7.21\right.$; d.f. $=5 ; P=0.20$; Fig. 1a). In both cases, by far the richest subfamilies were Myrmicinae and Formicinae, representing about one-half and one-quarter of total species, respectively. However, there were very considerable differences when considering proportional abundance $\left(\chi^{2}=\right.$ 80.81; d.f. $=5 ; \quad P<0.001$; Fig. 1b). Behaviourally dominant dolichoderines were proportionally far more abundant (around $65 \%$ of all individuals) in Australia, with myrmicines being likewise in Brazil. These differences were accounted by four genera: Iridomyrmex and Papyrius (Dolichoderinae, with $38 \%$ and $27 \%$ of all individuals, respectively) in Australia, and Pheidole and Solenopsis (Myrmicinae, with $41 \%$ and $25 \%$ of all individuals, respectively) in Brazil.

In Brazil, 48 species have arboreal nests (see Appendix S3), and these represented $>60 \%$ of ants collected on trees. In contrast, only five Australian species have arboreal nests, and these accounted for $<11 \%$ ants collected in arboreal traps. Even more notably, 22 of the Brazilian genera are of rainforest origin, accounting for 61 species, compared with just three genera each with a single species in Australia. This contrast would be even more striking if rainforest species groups within widely distributed genera such as Camponotus and Pheidole were considered. The contrast is epitomized by the ecologically comparable pseudomyrmecines Pseudomyrmex (Brazil) and Tetraponera (Australia), which were represented by 13 and 1 species, respectively.

The MDS plots based on species abundance showed a clear separation between the fauna from the ground and vegetation for Australia (Bray-Curtis similarity index of 0.27) and especially Brazil (Bray-Curtis
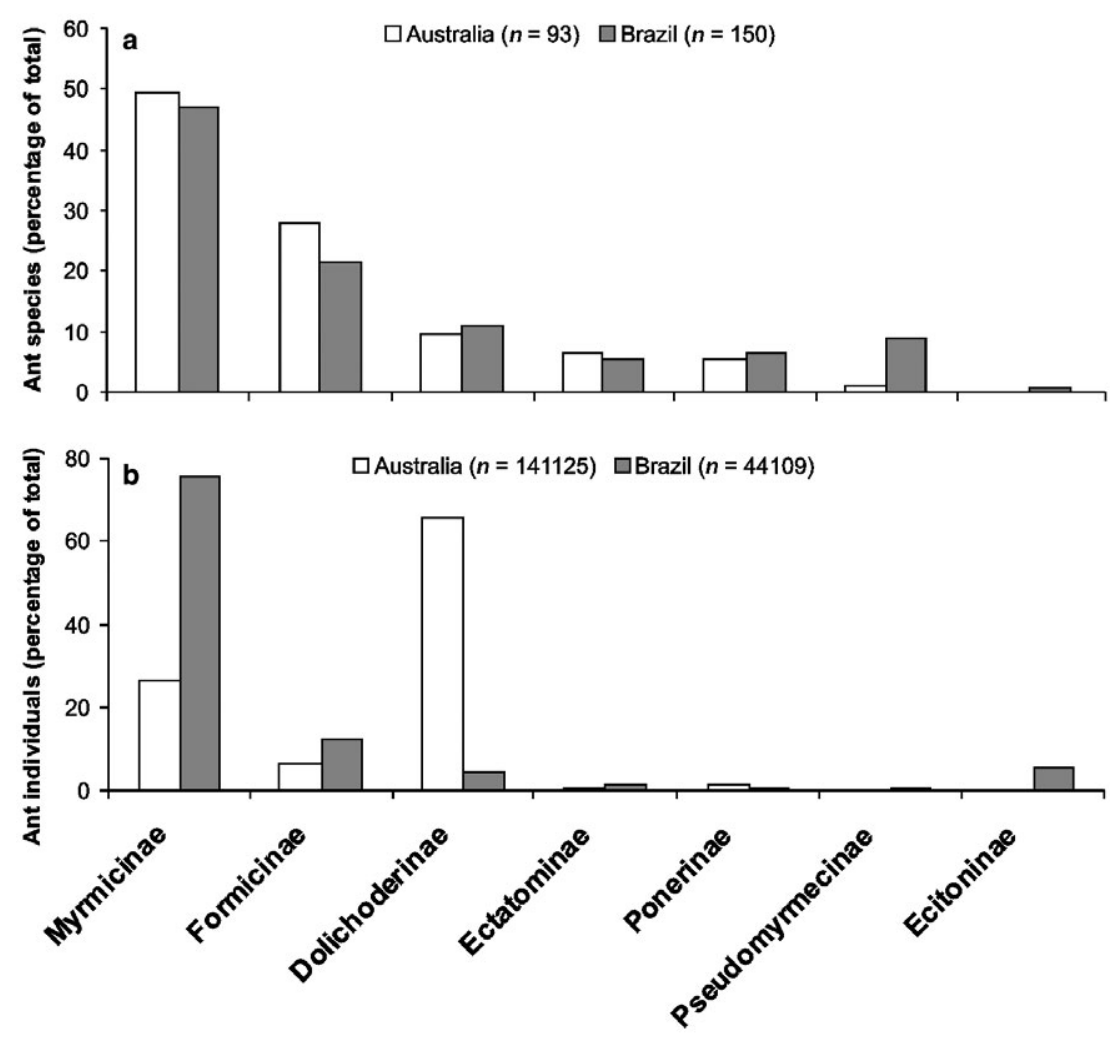

Fig. 1. Percentage of the total number of species (a) and individuals (b) by subfamily sampled in Australian savanna and Brazilian savanna. 

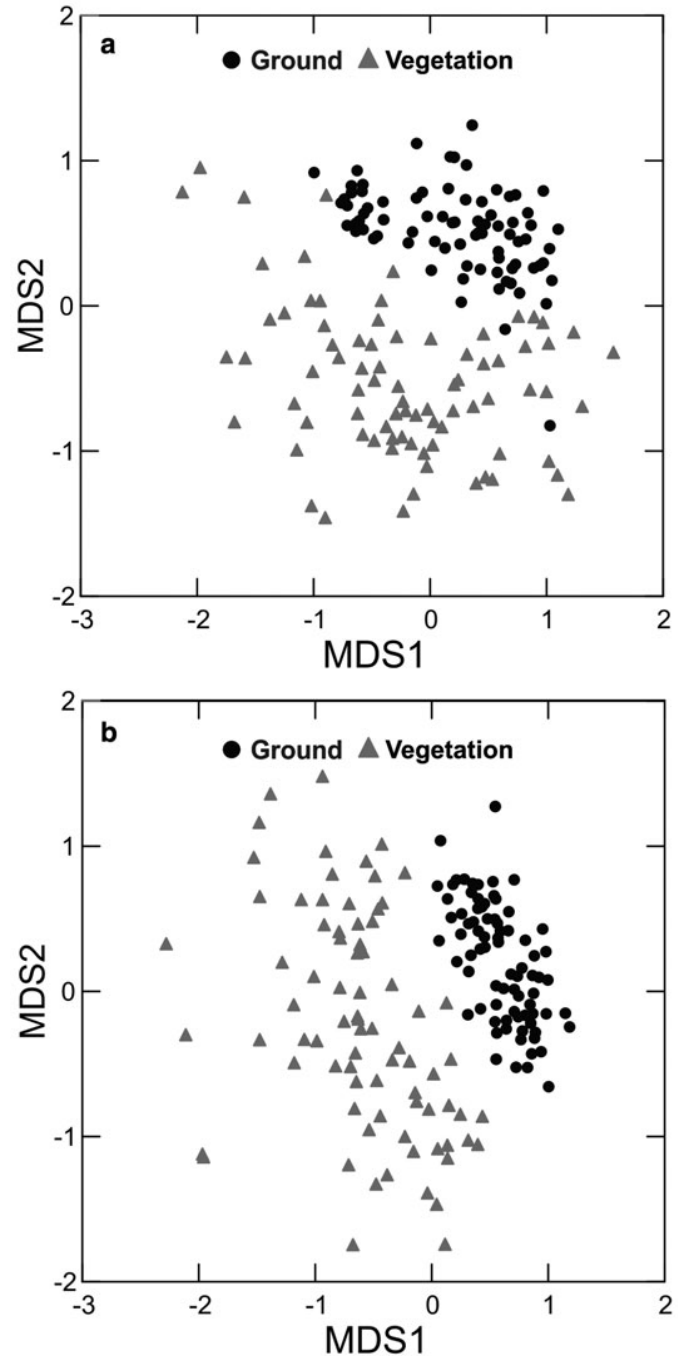

Fig. 2. Non-metric multidimensional scaling (MDS) showing differences in ant species composition between ground and vegetation in the savannas of Australia (a) and Brazil (b). Each point represents a different sampling unit ('tree') where four pitfalls were placed on the ground and four in the vegetation.

similarity index of 0.24 ) (MANOVA $P<0.001$ in both cases; Fig. 2). These intercontinental differences in between-stratum similarity were more pronounced when considering species occurrence rather than abundance, with Sørensen similarity indexes of 0.66 for Australia and 0.55 for Brazil. In Australia, 46\% of species were collected in both strata, compared with $38 \%$ in Brazil, and the proportion of species recorded exclusively in arboreal traps was twice as high in Brazil (9.3\%) compared with Australia (4.3\%).

\section{Ant abundance}

Overall ant abundance per pitfall was about three times higher in Australia than in Brazil, both on the ground and on vegetation (Ground, mean $\pm \mathrm{SE}$ : $409.5 \pm 30.7$ vs. $130.7 \pm 9.18, t=6.1$, d.f. $=638$, $P<0.001$; Vegetation: $31.8 \pm 5.4$ vs. $7.6 \pm 0.5$, $t=3.2$, d.f. $=638, P=0.001)$. This is further illustrated when we directly compare the total number of individuals of the most abundant species from both savannas (Australia: Iridomyrmex palli$d u s=34258$; Brazil: Pheidole fallax $=6646$ ).

\section{Species richness and species turnover}

Despite markedly lower ant abundance, overall species richness was far higher in Brazil (150 species) than in Australia (93; Appendix S4). The species abundance curves were extremely similar for the two faunas, with the difference in overall richness being driven by the number of rare species; there were 68 Brazilian species occurring in $<5$ trees, compared with only 25 in Australia $\left(\chi^{2}=8.27\right.$; d.f. $=1 ; P=0.003$; Fig. 3$)$.

Comparative species richness between Australia and Brazil varied markedly with spatial scale, with similar results for ground, arboreal and combined data. There was no significant difference in the mean number of species per pitfall trap (combined data: $t=1.48$; d.f. $=1278 ; \quad P=0.14$ ), but the mean number of species was significantly higher in Brazil than in Australia at both the tree and transect scales (combined data: $t=5.53$; d.f. $=158 ; P<0.001$; and $t=2.62$; d.f. $=6 ; P=0.04$, respectively; Fig. 4 ).

Partitioning of total species richness ( $\gamma$ diversity) in each country revealed that all observed diversity partitions are significantly different from those expected in a random distribution (Table 2). In both countries, the contribution to total diversity increased with spatial scale, with variation among trees within transects $(\beta 2)$ and among transects $(\beta 3)$ contributing a combined $80 \%$. However, variation among transects was substantially higher in Brazil (48\%) than Australia (35\%; Table 2). This can be explained by the greater geographic distances between transects in Brazil, given that species turnover at the transect scale increased with distance between transects (Fig. 5).

\section{DISCUSSION}

\section{Faunal composition}

The Australian and Brazilian savanna faunas showed remarkable compositional similarity at the subfamily level in terms of relative contribution to species richness, despite the very low proportion of shared genera. However, there were very marked intercontinental differences in subfamily composition in terms of contribution to relative abundance, with dolichoderines 


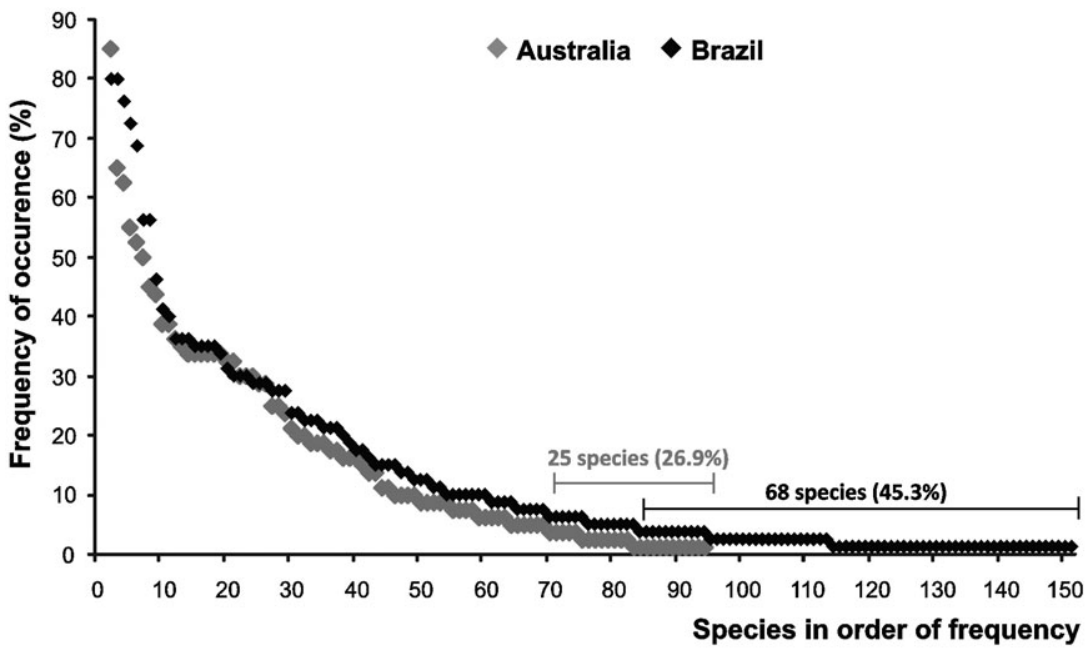

Fig. 3. Frequency-dominance curves showing the proportion of species sampled on less than $5 \%$ of the 'trees' in the Australian and Brazilian savannas. The species were ranked in order of frequency ( $n=80$ 'trees' by savanna).

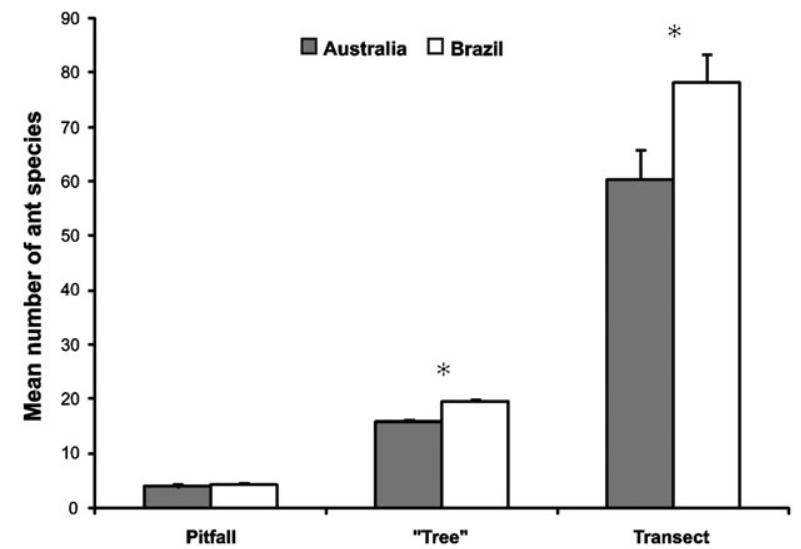

Fig. 4. Mean $( \pm S E)$ number of ant species at three different spatial scales: pitfalls $(n=640)$, 'tree' $(n=80)$ and transect $(n=4)$ in the Australian and Brazilian savannas. In each case, the symbols above the bars indicate significant differences $(P<0.05)$. Very similar results were shown when ground and arboreal results were analysed separately, and so these have not been presented.

(Iridomyrmex and Papyrius) being far more common in Australia, and myrmicines (Pheidole and Solenopsis) likewise in Brazil. This difference reflects the broader ecological domination of Australian ant communities by dolichoderines, which is unparalleled elsewhere in the world and arguably represents the most significant intercontinental 'anomaly' in ant biogeography and community ecology (Andersen 1995). Although the Brazilian species of Pheidole and Solenopsis can be considered as ecologically dominant ants, it is not a simple case of ecological equivalence to behaviourally dominant dolichoderines of Australia, as the myrmicines are functionally quite different in terms of their (lower) rates of activity and abundance (see below).
Ground-nesting behaviourally dominant dolichoderines (species of Dorymyrmex) occur in Brazilian savannas, but they tend to be minor components of ant communities in terms of abundance and behavioural dominance (Campos et al. 2006 unpubl. data).

There is also a major functional difference in the composition of the Australian and Brazilian savanna faunas in terms of nest location. The ground-active and arboreal faunas were quite distinct from each other in both countries, but especially so in Brazil, which had a dramatically higher representation of treenesting species. In Brazil, nearly 50 species collected on trees (representing more than $60 \%$ of total ants) have arboreal nests; whereas there were only five arboreal species, representing $11 \%$ of total ants, in Australia. Other studies have shown that arboreal ant fauna in Australian savannas contain few tree-nesting species and are dominated by ground-nesting species (Majer 1990; Andersen 2000; Andersen et al. 2006), and that Brazilian savannas have a high diversity of specialist arboreal ants (Ribas et al. 2003; da Silva et al. 2004; Vasconcelos \& Vilhena 2006; Campos et al. 2008). However, this is the first time that such differences have been explicitly examined and quantified.

Tree-nesting in Brazil occurs in a range of subfamilies, all of which occur in Australia, and in many genera, so this intercontinental contrast cannot be attributed to phylogenetic constraints. The most likely explanation lies in the contrasting biogeographic and evolutionary histories of the Australian and Brazilian savanna faunas. Australian savannas are biogeographically and evolutionarily associated with arid lands (Horton 1984), which characteristically have few specialist arboreal ants (Greenslade 1979; Andersen 2003). In contrast, Brazilian savannas are biogeographically and evolutionarily associated with 
Table 2. Additive partitioning of total ant species richness in Brazil and Australia into their alpha and beta components, using combined ground and arboreal data

\begin{tabular}{|c|c|c|c|c|}
\hline Country & Diversity component & Observed ( $\%$ of total) & Expected & $P$ \\
\hline \multirow[t]{5}{*}{ Australia } & $\alpha$ (within pitfalls) & $4.18(4.49)$ & 3.91 & $<0.001$ \\
\hline & $\beta 1$ (among pitfalls) & $11.73(12.61)$ & 17.31 & $<0.001$ \\
\hline & $\beta 2$ (among trees) & $44.59(47.95)$ & 53.54 & $<0.001$ \\
\hline & $\beta 3$ (among transects) & $32.50(34.95)$ & 18.24 & $<0.001$ \\
\hline & $\gamma$ (total diversity) & 93 & 92.99 & \\
\hline \multirow[t]{5}{*}{ Brazil } & $\alpha$ (within pitfalls) & $4.29(2.86)$ & 3.80 & $<0.001$ \\
\hline & $\beta 1$ (among pitfalls) & $15.16(10.11)$ & 15.60 & $<0.001$ \\
\hline & $\beta 2$ (among trees) & $58.80(39.20)$ & 54.78 & $<0.001$ \\
\hline & $\beta 3$ (among transects) & $71.75(47.83)$ & 50.01 & $<0.001$ \\
\hline & $\gamma$ (total diversity) & 150 & & \\
\hline
\end{tabular}

The $P$-values were obtained by comparing the observed values of each diversity component with expected values generated through 1000 randomizations of the dataset.

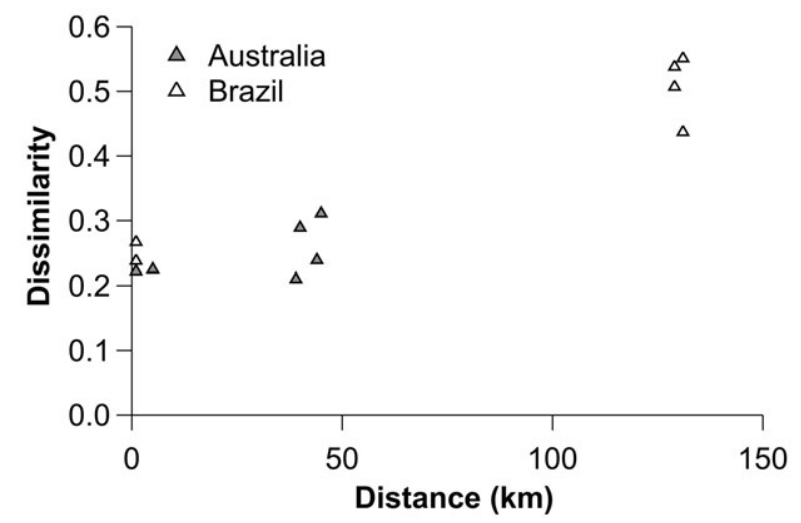

Fig. 5. Dissimilarity (Simpson index) in ant species composition between transects plotted against the geographical distance between the respective pair of transects.

rainforests (Redford \& Fonseca 1986), which characteristically support many arboreal specialists (Wilson 1959; Brühl et al. 1998; Longino et al. 2002). This explanation is supported by the fact that 22 of the genera that we collected in Brazilian savanna are of rainforest origin, accounting for 61 species, compared with just three genera and three species in Australia.

\section{Ant abundance}

Overall ant abundance was almost three times higher in Australia than in Brazil, both on the ground and on trees. This difference is consistent with the remarkably high ant productivity of arid, semi-arid and seasonally arid Australia (Andersen 2003), but this is the first time that standardized quantitative data have been obtained to document this difference. More specifically, much of the intercontinental difference is due to an extraordinarily high abundance of dolichoderines in Australia. Species of Iridomyrmex alone contributed to nearly $40 \%$ of total ant abundance in Australia, and the most common species in Australia (Iridomyrmex pallidus) was five times more abundant than the most common Brazilian species (Pheidole oxyops).

Extremely high ant productivity in Australia, and in particular the exceptional abundance of behaviourally dominant dolichoderines, has been linked to low soil fertility acting through the provision of liquid carbohydrates (Andersen 2003). Behaviourally dominant Iridomyrmex and other dolichoderines require liquid carbohydrates in the form of nectar or honeydew to maintain their large colony sizes and high rates of activity, as is the case for behaviourally dominant ants in general (Davidson 1997). Indeed, access to such liquid carbohydrate is the fundamental reason why groundnesting dolichoderines are so abundant in trees in Australia. The availability of liquid carbohydrate is strongly promoted by low soil fertility, as plants are limited by nutrients rather than by their ability to photosynthesize carbohydrate (Mattson 1980), such that Australia's characteristically infertile landscapes provide bountiful carbohydrate resources (StaffordSmith \& Morton 1990). Comparative data on the availability of liquid carbohydrates in Australia and Brazil are unavailable. However, despite being relatively infertile, Brazilian savanna soils are richer in nutrients than in Australian savannas (Montgomery \& Askew 1983), and we speculate that carbohydrate resources for ants might be lower in Brazil than Australia.

\section{Species richness and turnover}

Species richness was similar in Brazil and Australia at the pitfall scale, but was higher in Brazil at all larger scales. This parallels result from a comparative study of harvester ants in Australian and North American deserts, where richness was similar at small scales, but very considerably higher in Australia at larger scales as 
a result of a larger regional species pool and higher species turnover (Morton \& Davidson 1988). However, in our study the far higher total richness observed in Brazil (150 cf. 93 species) was influenced by its greater geographic separation of transects, which inflated species turnover among transects. We also acknowledge that our data are limited to single regions in each country. Therefore, further sampling is required both to assess continental differences in species turnover at larger spatial scales, and to verify the generality of our findings across the broader savanna biomes.

Nevertheless, the fact that local species richness varies markedly between such environmentally matched biomes indicates that comparative diversity is strongly influenced by regional factors (Andersen 2008). The most obvious regional factor is the available species pool, which explains comparative ant species richness in Australia and North America Andersen (1997b). In our study, comparative richness can be explained by the very large regional pool of rainforest taxa, including very many arboreal species in Brazil, a species pool that is virtually absent from savanna landscapes in Australia. Indeed, if species from rainforest taxa are excluded, the total number of species we recorded in Brazil (89) is almost identical to that in Australia (90). We have previously noted that Brazilian savannas are surrounded by vast expanses of tropical rainforests, the Amazon to the north and the Atlantic to the south, and that the evolutionary history of the savanna biota is embedded in expansions and retractions of rainforest (Redford \& Fonseca 1986; Silva \& Bates 2002). Such history is considered to be a major driver of the high local and regional diversity of birds (Silva 1997), mammals (Redford \& Fonseca 1986) and hawkmoths (Amorim et al.2009) in Brazilian savannas, and this also appears to be true for ants. In addition, within Brazilian savanna landscapes there are many intrusions of gallery and other mesophytic forests that are extremely rich in forest ant species (Lopes \& Vasconcelos 2008), whereas Australian savanna landscapes contain very small and isolated forest patches, and these support a depauperate ant fauna (Andersen et al. 2007).

In addition to specialist arboreal species, tropical rainforests also support a great diversity of cryptic species associated with the soil-litter interface (Ward 2000). Very few such species were recorded in our study, but cryptic ants are not well represented in pitfall samples. Australian savannas have a very depauperate cryptic ant fauna (Andersen 2000; Andersen et al. 2006), while in the savannas of Brazil cryptic species of the genera Gnamptogenys, Hylomyrma, Hypoponera, Prionopelta, Rogeria and Strumigenys are often collected by sorting the leaf-litter (Lopes \& Vasconcelos 2008). Consideration of cryptic taxa would therefore likely amplify intercontinental differences in savanna ant faunas driven by biogeographical context.
In addition to biogeographical context, there are two ecological factors that potentially contribute to higher ant diversity in Brazilian compared with Australian savannas. The first is a difference in structural complexity of savanna vegetation. Vegetation structure in Australian savanna woodlands is often strongly bimodal, with a poorly developed mid-storey. Moreover, Australian savannas are often dominated by just one or two tree species, such as Eucalyptus tetrodonta and E. miniata (Mott et al. 1985). In contrast, Brazilian savanna woodlands are multilayered (Ribeiro \&Walter 1998; Campos et al. 2008), which might promote ant richness through greater habitat heterogeneity (Ribas et al. 2003). Similarly, Brazilian savannas have greater tree species richness (Oliveira-Filho \& Ratter 2002) - we recorded a total of 41 tree species in Brazil, compared with only 19 in Australia. This might also contribute to greater ant species richness in Brazil, especially because there is a positive relationship between the number of tree species and ant richness in Brazilian savanna (Ribas et al. 2003). However, there is no evidence that ant richness varies substantially with tree richness or vegetation structural complexity in Australian savannas. Indeed, transect 1 had lowest ant richness (45, compared with 62-68 at others) despite its high vegetation complexity, and the relatively high tree richness at sites 1 and 4 (Table 1) was not associated with higher ant richness. This suggests that the relationship between tree and ant species richness in Brazil (Ribas et al. 2003) is contingent upon the regional availability of forest species, and especially tree-nesting specialists.

The second ecological factor potentially contributing to the observed intercontinental differences in ant richness is the higher abundance of behaviourally dominant ants, and therefore possibly higher rates of competitive exclusion, in Australia. However, this seems unlikely for two reasons. First, differences in competitive exclusion would affect comparative species richness at small spatial scales, whereas the differences we have revealed operate at larger spatial scales. Second, although competition from dominant ants can strongly affect foraging success of subordinate species, there is little evidence that it prevents such species from occurring (Gibb 2003; Andersen 2008). Indeed, within Australia there is a positive relationship between the abundance of behaviourally dominant dolichoderines and species richness (Andersen 1995).

\section{Concluding remarks}

Our study has revealed scale-dependent differences in species richness between savanna ants in Australia and Brazil. Species richness was similar at very small (pitfall trap) scales, but was increasingly higher in Brazil with increasing spatial scale. We have attributed these intercontinental differences in part to biogeo- 
graphical and historical factors in Brazil that have led to a large regional pool of species of rainforest origin. This further underlines the importance of biogeographical context when analysing ant communities, and further highlights the importance of processes acting at regional scales in determining species richness in ant communities (Kaspari et al. 2003; Parr et al. 2005; Andersen 2008).

Our study has compared savanna faunas at the highest end of the savanna rainfall gradient, and concluded that the large regional pool of rainforest taxa in Brazil has been a major factor contributing to higher species richness in Brazil compared with Australia. We would therefore predict that the intercontinental differences in species richness would diminish, and even be reversed, for savannas in lower rainfall zones. This is because the prevalence of rainforest taxa would be expected to decline with decreasing rainfall, with a concomitant favouring of arid-adapted taxa. Such a climatic shift would strongly change relative richness in Australia's favour. This would suggest that not only are cross-continental comparisons of species richness scale-dependent, but they are also likely to vary with the climate zone under investigation.

\section{ACKNOWLEDGEMENTS}

We are grateful to Cauê $\mathrm{T}$. Lopes and Clemence Goyens for helping with the field and laboratory work. We are also grateful to Andrew White, Paulo E. Oliveira and Celine de Melo for reading and commenting on a previous version of this manuscript. Thanks to Glein M. Araújo and Jon Schatz for kindly identified the plant species in Brazil and Australia, respectively. Finally, we would like to thank Renata P. Nascimento and Tatiane G. M. Silva for helping us with the statistical analyses. Logistical support was provided by the CSIRO Tropical Ecosystem Research Centre in Australia and Federal University of Uberlândia in Brazil. Financial support was provided by CAPES (international PhD fellowship to R.I.C), FAPEMIG (PhD grant to R.I.C), and FAP-DF (Projeto PRONEX 2009/00087-3, to H.L.V). All parts of this work comply with the current research laws of Brazil and Australia.

\section{REFERENCES}

Amorim F. W., Ávila R. S. Jr, Camargo A. J. A., Vieira A. L. \& Oliveira P. E. (2009) A hawkmoth crossroads? Species richness, seasonality and biogeographical affinities of Sphingidae in a Brazilian Cerrado. F. Biogeogr. 22, 15-29.

Andersen A. N. (1995) A classification of Australian ant communities based on functional-groups which parallel plant life-forms in relation to stress and disturbance. F. Biogeogr. $22,15-29$.
Andersen A. N. (1997a) Using ants as bioindicators: multi-scale issues in ant community ecology. Conserv. Ecol. 1, 8. [Cited August 2010.] Available from URL: http://www. ecologyandsociety.org/vol1/iss1/art8/

Andersen A. N. (1997b) Functional groups and patterns of organization in North American ant communities: a comparison with Australia. F. Biogeogr. 24, 433-60.

Andersen A. N. (2000) The Ants of Northern Australia: A Guide to the Monsoonal Fauna. CSIRO, Collingwood.

Andersen A. N. (2003) Ant biodiversity in arid Australia: productivity, species richness and community organization. Rec. S. Aust. Mus. 7, 79-92.

Andersen A. N. (2008) Not enough niches: non-equilibrial process promoting species co-existence in ant communities. Austral Ecol. 33, 211-20.

Andersen A. N., Hertog T. \& Woinarski J. C. Z. (2006) Long-term fire exclusion and ant community structure in an Australian tropical savanna: congruence with vegetation succession. F. Biogeogr. 33, 823-32.

Andersen A. N., van Ingen L. T. \& Campos R. I. (2007) Contrasting rainforest and savanna ant faunas in monsoonal northern Australia: a rainforest patch in a tropical savanna landscape. Aust. F. Zool. 55, 363-9.

Bolton B. (2003) Synopsis and classification of Formicidae. Mem. Am. Entomol. Inst. 71, 1-370.

Brown W. L. Jr (2000) Diversity of ants. In: Ants: Standard Methods for Measuring and Monitoring Biodiversity (eds D. Agosti, J. Majer, L. Alonso \& T. Schultz) pp. 45-79. Smithsonian Institution Press, Washington, DC.

Brühl C. A., Gunsalam G. \& Linsenmair K. E. (1998) Stratification of ants (Hymenoptera, Formicidae) in a primary rain forest in Sabah, Borneo. F. Trop. Ecol. 14, 285-97.

Campos R. I., Lopes C. T., Magalhães W. C. S. \& Vasconcelos H. L. (2008) Estratificação vertical de formigas em cerrado sentido restrito no Parque Estadual da Serra de Caldas Novas - GO. Iheringia Ser. Zool. 98, 311-16.

Clarke K. R. \& Warwick R. M. (2001) Change in Marine Communities: An Approach to Statistical Analysis and Interpretation, 2nd edn. PRIMER - E, Plymouth.

Cody M. \& Mooney H. (1978) Convergence versus nonconvergerce in mediterranean climate ecosystems. Annu. Rev. Ecol. Syst. 9, 265-321.

Colwell R. K. (2004) EstimateS: statistical estimation of species richness and shared species from samples, version 7.5. User's guide and application. [Cited 20 December 2010.] Available from URL: http://viceroy.eeb.uconn.edu/estimates

da Silva R. R., Brandão C. R. F. \& Silvestre R. (2004) Similarity between Cerrado Localities in central and southeastern Brazil based on the dry season bait visitors ant fauna. Stud. Neotrop. Fauna E. 39, 191-9.

Davidson D. W. (1997) The role of resource imbalances in the evolutionary ecology of tropical arboreal ants. Biol. F. Linn. Soc. 61, 153-81.

Dunn R. R., Agosti D., Andersen A. N. et al. (2009) Climatic drivers of hemispheric asymmetry in global patterns of ant species richness. Ecol. Lett. 12, 324-33.

Gibb H. (2003) Dominant meat ants affect only their specialist predator in an epigaeic arthropod community. Oecologia 136, 609-15.

Gotelli N. J. \& Colwell R. K. (2001) Quantifying biodiversity: procedures and pitfalls in the measurement and comparison of species richness. Ecol. Lett. 4, 379-91.

Gotelli N. J. \& Ellison A. M. (2002) Biogeography at a regional scale: determinants of ant species density in New England bogs and forests. Ecology 83, 1604-9. 
Greenslade P. J. M. (1979) A Guide to Ants of South Australia. South Australian Museum, Adelaide.

Horton D. R. (1984) Dispersal and speciation: pleistocene biogeography and the modern Australian biota. In: Vertebrate Zoogeography and Evolution in Australasia: Animals in Space and Time (eds M. Archer \& G. Clayton) pp. 113-18. Hesperan Press, Sydney.

Huntley B. J. \& Walker B. H. (1982) Ecology of Tropical Savannas. Springer-Verlag, Berlin.

Kaspari M., Yuan M. \& Alonso L. (2003) Spatial grain and the causes of regional diversity gradients in ants. Am. Nat. 161, 459-77.

Kempf W. W. (1972) Catálogo abreviado das formigas da região Neotropical. Stud. Entomol. 15, 3-344.

Koleff P., Gaston K. J. \& Lennon J. J. (2003) Measuring beta diversity for presence-absence data. F. Anim. Ecol. 72, 367-82.

Lawton J. H. (1999) Are there general laws in ecology? Oikos 84, 177-92.

Longino J. T., Coddington J. \& Colwell R. K. (2002) The ant fauna of a tropical rain forest: estimating species richness three different ways. Ecology 83, 689-702.

Lopes C. T. \& Vasconcelos H. L. (2008) Evaluation of three methods for sampling ants in the Brazilian Cerrado. Neotrop. Entomol. 37, 399-405.

Majer J. D. (1990) The abundance and diversity of arboreal ants in northern Australia. Biotropica 22, 191-9.

Mattson W. J. Jr (1980) Herbivory in relation to plant nitrogen content. Ann. Rev. Ecol. Syst. 11, 119-61.

Montgomery R. F. \& Askew G. P. (1983) Soils of tropical savannas. In: Ecosystems of the World Vol. 13, Tropical Savannas (ed. F. Bourlière) pp. 63-78. Elsevier, Amsterdam.

Morton S.W. \& Davidson D.W. (1988) Comparative structure of harvester ant communities in arid Australia and NorthAmerica. Ecol. Monogr. 58, 19-38.

Mott J. J., Williams J., Andrew M. H. \& Gillison A. N. (1985) Australia savanna ecosystems. In: Ecology and Management of the World's Savanna (eds J. C. Tothill \& J. J. Mott) pp. 56-82. Australian Academy of Science, Canberra.

Oliveira P. S. \& Marquis R. (2002) Introduction: development of research in the Cerrados. In: The Cerrados of Brazil: Ecology and Natural History of a Neotropical Savanna (eds P. S. Oliveira \& R. J. Marquis) pp. 1-10. Columbia University Press, Columbia.

Oliveira-Filho A. T. \& Ratter J. A. (2002) Vegetation physiognomies and wood flora of the Cerrado Biome. In: The Cerrados of Brazil: Ecology and Natural History of a Neotropical Savanna (eds P. S. Oliveira \& R. J. Marquis) pp. 91-120. Columbia University Press, Columbia.

Parr C. L. \& Chown S. L. (2001) Inventory and bioindicator sampling: testing pitfall and Winkler methods with ants in a South African savanna. F. Insect Conserv. 5, 27-36.

Parr C. L., Sinclair B. J., Andersen A. N., Gaston K. J. \& Chown S. L. (2005) Constraint and competition in assemblages: a cross-continental and modeling approach for ants. Am. Nat. $165,481-94$.

Redford K. H. \& Fonseca G. (1986) The role of gallery forest in the zoogeography of the cerrado's non-volant mammalian fauna. Biotropica 18, 126-35.

Ribas C. R., Schoereder J. H., Pic M. \& Soares S. M. (2003) Tree heterogeneity, resource availability, and larger scale processes regulating arboreal ant species richness. Austral Ecol. 28, 305-14.

Ribeiro J. F. \& Walter B. M. T. (1998) Fitofisionomias do bioma Cerrado. In: Cerrado: Ambiente e Flora (eds S. M. Sano \& S. P. Almeida) pp. 89-166. Embrapa, Brasília.
Ricklefs R. E. (1987) Community diversity - relative roles of local and regional processes. Science 235, 167-71.

Schultz T. R. \& McGlynn T. P. (2000) The interactions of ants with other organisms. In: Ants: Standard Methods for Measuring and Monitoring Biodiversity (eds D. Agosti, J. Majer, L. Alonso \& T. R. Schultz) pp. 35-44. Smithsonian Institution Press, Washington, DC.

Silva J. M. C. (1997) Endemic bird species and conservation in the Cerrado Region, South America. Biodivers. Conserv. 6, $435-50$.

Silva J. M. C. \& Bates J. M. (2002) Biogeographic patterns and conservation in the South American Cerrado: a tropical savanna hotspot. BioScience 52, 225-33.

Spiesman B. J. \& Cumming G. S. (2008) Communities in context: the influences of multiscale environmental variation on local ant community structure. Landsc. Ecol. 23, 313-25.

SPSS Inc. (2000) Systat ${ }^{\circledR}$ Version 10.0. SPSS Inc., Chicago.

Stafford-Smith D. M. \& Morton S. R. (1990) A framework for the ecology of arid Australia. F. Arid Environ. 18, 255-78.

Taylor R. W. (1972) Biogeography of insects in New Guinea and Cape York Peninsula. In: Bridge and Barrier: The Natural and Cultural History of Torres Strait (ed. D. Walker) pp. 213-30. Australian National University Press, Canberra.

Vasconcelos H. L. \& Vilhena J. M. S. (2006) Species turnover and vertical partitioning of ant assemblages in the Brazilian Amazon: a comparison of forests and savannas. Biotropica 38, 100-6.

Veech J. A. \& Crist T. O. (2009) PARTITION: software for hierarchical additive partitioning of species diversity, version 3.0. [Cited December 2010.] Available from URL: http:// www.users.muohio.edu/cristto/partition.htm

Veech J. A., Summerville K. S., Crist T. O. \& Gering J. C. (2002) The additive partitioning of species diversity: recent revival of an old idea. Oikos $99,3-9$.

Ward P. S. (2000) Broad-scale patterns of diversity in leaf litter ant communities. In: Ants: Standard Methods for Measuring and Motoring Biodiversity (eds D. Agosti, J. D. Majer, L. E. Alonso \& T. R. Schultz) pp. 99-101. Smithsonian Institution Press, Washington, DC.

Whittaker R. J., Willis K. J. \& Field R. (2001) Scale and species richness: towards a general, hierarchical theory of species diversity. F. Biogeogr. 28, 453-70.

Wiens J. A. (1989) Spatial scaling in ecology. Funct. Ecol. 3, 385-97.

Wilson E. O. (1959) Some ecological characteristics of ants in New Guinean rain forests. Ecology 40, 437-47.

Zar J. (1999) Biostatistical Analysis, 4th edn. Prentice Hall, Upper Saddle River, New Jersey.

\section{SUPPORTING INFORMATION}

Additional Supporting Information may be found in the online version of this article:

Appendix S1. Photographs of representative vegetation of study sites in Australia.

Appendix S2. Diagram showing the three different spatial scales of sampling.

Appendix S3. Number of species within different ant genera collected in each savanna (Australian and Brazilian).

Appendix S4. Cumulative number of ant species recorded in the Australian and Brazilian savannas. 